
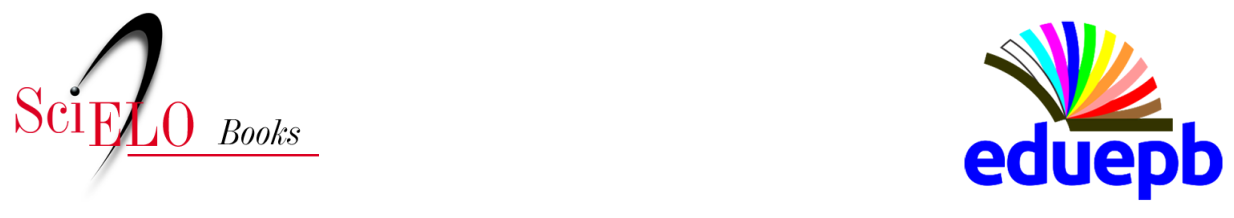

\title{
O Uso das NTICS em Sala de Aula de Língua Inglesa: o caso do aplicativo de mensagem, via aparelho móvel celular
}

\author{
Jordânia Virgínio dos Santos \\ Ivandilson Costa
}

\section{SciELO Books / SciELO Livros / SciELO Libros}

SANTOS, J. V., and COSTA, I. O Uso das NTICS em Sala de Aula de Língua Inglesa: o caso do aplicativo de mensagem, via aparelho móvel celular. In: ARANHA, S. D. G., and SOUZA, F. M., eds. Práticas de ensino e tecnologias digitais [online]. Campina Grande: EDUEPB, 2018, pp. 55-90. Ensino e aprendizagem collection, vol. 3. ISBN: 978-85-78795-26-9. http://doi.org/10.7476/9786586221657.0004.

\section{(c) $\underset{\mathrm{EY}}{(\mathrm{i})}$}

All the contents of this work, except where otherwise noted, is licensed under a Creative Commons Attribution 4.0 International license.

Todo o conteúdo deste trabalho, exceto quando houver ressalva, é publicado sob a licença Creative Commons Atribição 4.0.

Todo el contenido de esta obra, excepto donde se indique lo contrario, está bajo licencia de la licencia Creative Commons Reconocimento 4.0. 


\title{
O USO DAS NTICs EM SALA DE AULA DE LÍNGUA INGLESA: o caso do aplicativo de mensagem, via aparelho móvel celular
}

\author{
Jordânia Virgínio dos Santos ${ }^{1}$ \\ Ivandilson Costa ${ }^{2}$
}

\section{Introdução}

Historicamente observamos que o mundo desde sua pré-história vem sendo modificado pelo surgimento de novas tecnologias, passando pelas mais simples até as formas de comunicação mais avançadas que temos nos dias de hoje. Junto com esses grandes avanços tecnológicos vem crescendo também o conhecimento humano, fazendo assim uma certa exigência da incorporação dessas tecnologias no ambiente de ensino.

Vivemos em um mundo onde o desenvolvimento tecnológico e a utilização das novas tecnologias da informação e comunicação (NTICs), vêm crescendo cada vez mais. Atualmente se pararmos para observar em uma sala de aula, perceberemos que a maioria dos alunos tem um

1 Graduada em Letras/Língua Inglesa pela Universidade do Estado do Rio Grande do Norte (UERN), Núcleo Avançado de Ensino Superior de Macau (NAESM).

2 Doutor em Letras/Linguística pela UFPE. Professor Adjunto da UERN, Departamento de Letras Estrangeiras. 
aparelho móvel celular e, partindo desse contexto, muitos educadores tiveram que fazer uma revisão nas suas formas de ensinar, pois, como as NTICs já estão automaticamente inseridas no nosso cotidiano, esses professores precisam estar preparados para inseri-las em sua sala de aula, adequando-se à realidade em que esses alunos se encontram e também passar a enxergar as NTICs como um aliado para facilitar ainda mais o aprendizado. Não obstante, nota-se que mesmo já fazendo parte do nosso cotidiano ainda existe uma certa rejeição por parte de alguns professores.

Partindo desse ponto, buscamos tratar de um tipo específico de mídia social, o uso do aplicativo de troca de mensagens por aparelho móvel, WhatsApp Messenger, como um aliado para o ensino de língua inglesa. Mostraremos, através de um diagnóstico, como elas podem ajudar a melhorar o conhecimento de professores e alunos nesse campo de aprendizagem e, por consequência, apresentaremos um quadro sugestivo, demonstrando de que forma o aplicativo WhatsApp poderia ajudá-los.

Nessa perspectiva, a escolha por tal aplicativo se justifica, principalmente pelo fato de que a maioria dos alunos hoje faz uso do WhatsApp, para diversas atividades, como por exemplo: tirar e compartilhar fotos, gravar, enviar e escutar/ver áudios e vídeos, usar do sistema de messenger (bate-papo). Além disso, percebemos que, como é ainda comum em muitas escolas públicas e de regiões de base mais rural, como é o caso da localidade foco de nossa investigação, a cidade de Pendências (RN), existe ainda uma certa carência em se tratando da aplicação de novas tecnologias no ensino de língua inglesa. É, portanto, pretensão de nossa pesquisa fornecer bases para 
subsidiar professores, quanto ao emprego de NTICs como um aliado ao processo de ensino-aprendizagem, especialmente de língua inglesa.

Diante desse quadro, cumprindo um objetivo principal do trabalho, foi feito um diagnóstico de como se encontram os estudos atualmente sobre as NTICs e sua relação com o ensino de Língua Inglesa, para, a partir disso, apresentarmos um quadro panorâmico de como pode ser utilizado em sala de aula. Elaboramos, nesse sentido, um apanhado teórico de como vem sendo tratado o uso das NTICs aplicáveis a aulas de língua inglesa, bem como fornecemos subsídios para a construção de procedimentos para trabalhar com o aplicativo de troca de mensagens em aulas de língua inglesa. Construímos, ainda, procedimentos de trabalho com o aplicativo, com o cuidado de que seja adequado a turmas de língua inglesa do ensino fundamental II, foco da pesquisa.

O trabalho se enquadra no âmbito de uma pesquisa bibliográfica, pois buscamos mostrar, através de investigações já realizadas, como o uso das NTICs pode ajudar a melhorar o ensino aprendizagem de língua estrangeira. Trata-se, desse modo, de pesquisa "desenvolvida a partir de material já elaborado, constituído principalmente de livros e artigos científicos" (GIL, 2008, p. 32).

A proposta se desenvolveu, portanto, pelo levantamento em bibliografia especializada, de sugestões e métodos de utilização de NTICs no ensino de língua inglesa, delimitando-se em um apanhado de trabalhos já publicados em literatura especializada, periódicos inclusive, em plataformas digitais inclusive, sobre o tema específico do uso de aplicativos de troca de mensagem para celular e seu uso no ensino de língua inglesa. 
Posteriormente, foi elaborada uma proposta de trabalho em sala de aula para o público do ensino fundamental, a partir da construção de quadros sob o formato de sequências didáticas, para o fim específico de se tratar dos seguintes pontos especialmente: ensino da compreensão oral, ensino da escrita e ensino do vocabulário. As sequências didáticas são compostas dos seguintes componentes: conteúdo; dados da aula (o que o aluno pode aprender, duração das atividades, conhecimentos prévios); estratégias e recursos; recursos complementares; avaliação.

\section{Ensino de Inglês e tecnologias: o uso de aplicativos como um instrumental didático}

Ensino de Lingua Estrangeira (LE)

e ensino de Lingua Inglesa (LI)

$\mathrm{O}$ ensino de língua estrangeira, principalmente o da língua inglesa, passou por várias mudanças desde as últimas décadas. Foram criados métodos e abordagens, e, quando se fala em ensino de LE, é preciso conhecer os principais métodos, que são: Método Tradicional (ou método da gramática-tradução), Método Direto, Método Audiolingual e a Abordagem Comunicativa.

Segundo Leffa (1988), a abordagem da gramática e da tradução (AGT) é conhecida também como método, tendo sido a metodologia com mais tempo de uso na história de ensino de línguas, ainda hoje utilizada. Ela consiste no ensino da segunda língua pela primeira e toda informação é dada através de explicações na língua materna do aluno. Aquele autor ainda cita três passos essenciais para aprendizagem da língua, que são: “(a) memorização prévia de 
uma lista de palavras, (b) conhecimento das regras necessárias para juntar essas palavras em frase e (c) exercícios de tradução e versão (tema)" (LEFFA, 1988, p.34).

No método direto acontece o contrário da AGT, pois o aluno deve aprender a L2 pela L2 e a língua materna nunca deve ser utilizada na sala de aula. Os significados se dão através de gestos e gravuras, em que não se pode recorrer ao método da tradução. Já o método audiolingual tem objetivo de levar o aprendiz a comunicar-se na língua-alvo através da formação de novos hábitos linguísticos. A abordagem comunicativa, por seu lado, caracteriza-se por ter o foco no sentido, no significado e na interação entres os aprendizes de uma nova língua.

Já Oliveira (2014) elabora grandes questões teóricas para o ensino do Inglês, para o que destaca o conceito de método. Nesse âmbito, aborda, além dos aqui levantados, ainda os métodos como a abordagem oral, o método audiolingual, os métodos alternativos (Silent Way, Suggestopedia, Total Physical Response-TPR, Community Language Learning- CLL) e os métodos comunicativos (abordagem natural, abordagem comunicativa, abordagem baseada em tarefas, abordagem intercultural).

Mais posteriormente, aquele autor (OLIVEIRA, 2015) destaca como um grande desafio no campo do ensino de LI: o desenvolvimento da habilidade oral na segunda língua. Ele considera que a compreensão oral é a habilidade que mais desafios apresenta para os aprendizes brasileiros. Remonta, assim, às atividades de pré-compreensão, contemplando quatro micro-habilidades: a busca por informações específicas, o reconhecimento de palavras, a busca por ideias gerais e a inferenciação. E prossegue ressaltando a importância de uma questão premente nos 
tempos de hoje: o uso dos recursos tecnológicos no ensino da compreensão oral.

Segundo Donnini, Platero e Weigel (2010, p.15), a concepção de língua como sistema e estrutura se faz presente no ensino de línguas estrangeiras de modo bastante significativo e que a abordagem oral ou situacional (The Oral Approach ou Situational Language Teaching) foi uma das primeiras metodologias concebidas. Essa metodologia está fundamentada em três pilares: o uso de vocabulário, o controle de estruturas gramaticais e a apresentação de ambos em situações, como, por exemplo, uso de objetos concretos ou representações gráficas que venham possibilitar a associação direta entre o conteúdo e seu significado.

Já o método audiolingual, conhecido também como audiovisual, ainda segundo Donnini, Platero e Weigel (2010 p.16), "incorporou a ênfase na estrutura linguística presente desde o método direto (ou método de Berlitz)". As autoras dizem que esse foi um evento marcante na história do ensino de línguas, pois foi o primeiro a ganhar o status de método cientifico e que os seus procedimentos estariam todos fundamentados, testados e comprovados por linguistas e psicólogos.

Com os métodos situacional e audiovisual, surgiram várias outras manifestações de métodos alternativos, como, por exemplo, sugestologia (suggestopedia), o ensino silencioso (silent way), a resposta física total (TPRtotal physical response), o ensino comunitário (community language teaching), entre outros. Para Donnini, Platero e Weigel (2010 p.17), esses métodos:

Constituíram ensaios de respostas à concepção de aprendizagem comportamentalista, sem, no entanto, 
encontrarem muita adesão entre os professores, quando comparados à força adquirida pelos métodos audiovisual e situacional.

Posteriormente, as autoras falam sobre o surgimento do método comunicativo no ensino de línguas. O objetivo desse método é desenvolver a proficiência comunicativa, tendo foco no sentido, ou seja, no significado, na interação entre os falantes. Como exemplo, em uma aula onde esse método está presente, o professor age como coordenador e facilitador, fornece materiais e situações para que o aluno possa ter uma aprendizagem real.

Além disso, as quatros habilidades (ouvir, falar, ler e escrever) estão imbricadas na manifestação da competência comunicativa e em contextos de seu uso real, pois muitas vezes vivenciamos situações em que precisamos fazer utilização de mais de uma dessas habilidades ao mesmo tempo.

Portanto, para que todos esses métodos citados anteriormente cheguem até a sala de aula, eles necessitam do professor e não podemos deixar de falar no seu papel que é de grande importância, pois é através dele que os alunos vão se apropriar dos saberes escolares e se tornarem críticos e autônomos. Segundo Gandour (2014, p.157):

Os professores, sendo os maiores conhecedores das necessidades sociais e educacionais dos alunos, devem contribuir e participar de forma mais efetiva nos diversos eventos que compõem o processo pedagógico. 
Daí a importância de ser um professor reflexivo, ou seja, professor que reflete sobre sua prática de ensino, com o intuito de modificá-la, melhorando não só para benefício próprio, mas para todos aqueles que fazem parte da comunidade escolar. Ser um professor reflexivo não é só transmitir conteúdo, é atuar na interação com os alunos e toda a comunidade, é ser responsável por aquilo que acredita ser o certo, adequando-se à realidade, ao levar essa teoria para a sala de aula, visando principalmente as necessidades dos alunos.

Muitas vezes o professor participa de quase todas as etapas de vida de um aluno como por exemplo, crianças, jovens e adultos, mas algumas vezes a fase da adolescência é a mais temida por parte de alguns, por ser uma fase difícil de lidar. Basso (2008 p.115) lembra que os adolescentes muitas vezes são rotulados como "aborrescentes, cansativos, malcriados, barulhentos, distraídos, agressivos, difíceis..." e ainda ressalta que a lista para descrever os adolescentes é longa e também é quase sempre carregada de significação negativa e preconceitos por parte dos pais, professores ou adultos em geral.

Não se pode negar que é mesmo uma fase difícil, mas os professores têm que saber lidar com essa fase, pois faz parte da profissão daqueles que trabalham com o ensino fundamental e ensino médio e é normal tê-los em volta. Mas o "saber lidar" está envolvido com a formação do próprio professor também. É importante ter uma boa formação para que esses adolescentes não venham ser rejeitados também no ambiente de ensino.

Outro ponto importante é a produção de materiais autênticos, documentos escritos ou orais que permitem que o aluno tenha contato com a língua estrangeira e sua 
cultura. As NTICs podem ser tomadas como um bom exemplo de tais recursos, para aquisição da aprendizagem de língua estrangeira, como materiais que venham auxiliar na escrita e leitura no ensino de línguas.

Em uma coleção editada por Tomlinson (1998) que tem por título "Materiais Desenvolvimento em Ensino de Línguas", vemos que se faz pouca referência à contribuição de computadores, diferentemente do que faz Maley (1998), quando diz que estamos no início de uma geração na qual os materiais para o ensino de línguas são informatizados.

Segundo Chapelle (2001, p. 2), uma pessoa que se preocupa com a linguagem de ensinar no século XXI "precisa compreender a natureza das tarefas únicas mediadas por tecnologia que os alunos podem participar". Dessa forma, é sabido afirmar a importância dos materiais eletrônicos como ferramenta no ensino de línguas, pois estão interligados com a nova geração à qual os alunos pertencem.

Assim, como esses autores tratam as tecnologias como auxiliadoras no processo de ensino-aprendizagem, devemos também usá-las para aperfeiçoar o ensino de línguas, pois favorece essa nova geração que está cada vez mais ligada as novidades da tecnologia, e, com isso, podemos tratar a tecnologia como um método de ensino.

\section{TICs e ensino}

Paiva (2013) faz uma breve apresentação histórica sobre o uso de tecnologias no ensino de língua estrangeira, começando pelos recursos tipográficos até o desenvolvimento dos equipamentos eletrônicos. Na visão da autora, 
o ensino de línguas nas escolas busca inserir as novas tecnologias nas práticas pedagógicas, como uma tentativa de melhorar a mediação entre os alunos e a língua alvo. Nesse contexto, o professor que utilizar as tecnologias em suas aulas certamente estará contribuindo com o processo de aprendizagem de seus alunos.

As novas tecnologias estão cada vez mais presentes em nossas vidas e mudou a maneira de pensar da sociedade. Diante desse cenário, a cada dia um novo dispositivo é criado, em que pese o fato de que a educação básica se encontra há tempos mantendo-se dentro das mesmas diretrizes e sem nenhuma evolução ou mudança concreta. Assim, se para os professores antes, era difícil manter a atenção de seus alunos, que não tinham em mãos ferramentas que os distraíssem, hoje essa tarefa se tornou quase impossível.

Muitos professores ainda não se sentem seguros para utilizar as novas tecnologias em sala de aula por vários motivos, como por exemplo, não saber usar o computador e seus recursos como ferramenta pedagógica. Acreditamos que a dificuldade é atribuída a vários fatores como a deficiência na formação profissional, a falta de tempo, o pouco incentivo da própria escola para o aprimoramento desses professores. Segundo Kenski:

É necessário, sobretudo, que os professores se sintam confortáveis para utilizar esses novos auxiliares didáticos. Estar confortável significa conhecê-los, dominar os principais procedimentos técnicos para sua utilização, avaliá-los criticamente e criar novas possibilidades pedagógicas, 
partindo da integração desses meios com o processo de ensino (KENSKI 2003, p.77).

Hoje, esses alunos que já nascem na era digital fazem o uso constante de ferramentas tecnológicas que lhes permitem fazer pesquisas, comunicar-se e publicar, mas nem sempre fazem o uso dessas tecnologias com propósito de autoaprendizagem. É por essa razão que o professor tem um papel essencial pois é ele quem deve dar direcionamentos de como utilizar tais ferramentas para o ensino e aprendizagem. Mas não são só essas barreiras enfrentadas, quando se trata da utilização dessas novas tecnologias da informação e comunicação no ensino. Santos, Beato e Aragão (2012) citam algumas barreiras encontradas: "[...] níveis de confiança, quantidade de suporte técnico disponível, qualidade da formação, ausência de conhecimento técnico para operar os equipamentos, resistência à mudança".

Quando existem essas barreiras, elas afetam a utilização das novas tecnologias, pois os profissionais têm que saber dominá-las para se sentir confiantes perante os alunos. Mas, para que exista esse domínio, os professores têm que ter uma boa formação para que não venha resistir à mudança por não saber utilizá-las. Caberá à escola assumir novos papeis para suprir as necessidades desses professores, disponibilizado cursos para capacitá-los.

Portanto, vale lembrar que não é só ter essas tecnologias na escola, mas oferecer um ensino aos profissionais para que venham aperfeiçoar o conhecimento já existente e usá-las em benefício de todos. Do contrário, se não acontecer essa mudança, todos os equipamentos tecnológicos 
ficarão guardados dentro de caixas sem poderem ser utilizado, porque não se saber lidar com eles. É preciso investir na formação dos professores, pois é através deles que podemos pensar na transformação da escola nesse sentido.

NTICs e ensino de LE

Não se pode negar que, assim como o ensino de outras práticas pedagógicas, o ensino de língua estrangeira também tem tido como benefício o uso de novas tecnologias da informação e comunicação, mas também tem gerado grande discussões sobre esse novo modelo de aprendizagem mediado por dispositivos móveis.

As NTICs vêm auxiliando o ensino de LE. Nas duas últimas décadas esse auxilio se tornou muito importante em ambientes de ensino-aprendizagem. Hoje, com ajuda da internet e através de aparelhos móveis, seja ele o celular, o tablet ou o próprio notebook, o aluno tem uma grande facilidade de desfrutar de uma gama de serviços que podem ajudar no seu aprendizado, como, por exemplo, as bibliotecas virtuais, os bate-papos, os correios eletrônicos, as redes sociais, entre outros.

Essa realidade que estamos vivenciando, da união das NTICs com o ensino de línguas é um fator muito importante e que, a partir dessa união, tem gerado grandes benefícios para a educação. Mas, segundo Lopes (2012, p.5), muitas instituições ainda apresentam dificuldades para inserir essas tecnologias na sala de aula e se adequarem aos tempos atuais. Ela afirma que: 
As novas tecnologias de informação e comunicação têm influenciado significativamente a educação, de modo a realçar a sua importância para o desenvolvimento social. Muitas instituições de ensino, no entanto, ainda apresentam grandes dificuldades para adequarem-se às rápidas transformações dos tempos atuais. Isto porque as novas demandas tecnológicas exigem dos alunos capacidade de raciocínio, habilidades verbais e numéricas específicas, maior poder de reflexão e criação de novas formas de conhecimento (LOPES, 2012, p.5).

Já para Kenski a educação tem um papel fundamental, pois é por meio dela que podemos ter acesso ao conhecimento necessário e, a partir desse conhecimento, é que poderemos dominar as tecnologias e compreendê-las melhor. Entretanto, a educação tem esse desafio de desempenhar esse papel, e também adaptar-se a essa nova realidade de um mundo tecnológico. Ela afirma que "esse também é um duplo desafio da educação: adaptar-se aos avanços das tecnologias e orientar o caminho de todos para o domínio e apropriação crítica desses novos meios" (KENSKI, 2008, p.18).

$\mathrm{Na}$ área educacional, vem crescendo o número de dispositivos móveis e recursos digitais que promovem mudanças no modelo tradicional da educação. Com o surgimento dos recursos tecnológicos, nasceu o EAD (ensino à distância), modelo de ensino conhecido desde o século XIX, e que nasceu da necessidade 
de preparar profissionalmente pessoas que, por vários motivos, não podiam estar presentes em um ambiente de ensino presencial. Esse tipo de ensino contempla também o desenvolvimento da autonomia do próprio aluno, pois ele é desafiado a pesquisar o conteúdo e entendê-lo.

Tal modalidade se encaixa no modelo $e$ - Learning, que resulta de uma combinação ocorrida entre o ensino com auxílio da tecnologia e educação a distância, é concentrado em educação online. Assim como o ensino a distância, existem outras ferramentas tecnológicas que permitem que o aluno tenha um perfil autônomo e vá em busca do seu próprio conhecimento, como, por exemplo, o celular, o notebook ou tablet. Essas são ferramentas que geralmente estão mais presentes na vida dos jovens e, por isso, elas podem ajudar no aprendizado desses alunos.

Quando o aluno tem o interesse pelo desenvolvimento da língua estrangeira, ele apela para algumas coisas fora do ambiente de ensino, como por exemplo, ouvir música, assistir TV, assistir filmes com legendas, conversar com outros falantes da língua, entre outras atividades. Mas, segundo Paiva (2009, p. 33), isso raramente acontece dentro da escola:

A sala de aula, geralmente, não oferece atividades de uso da língua, mas apenas exercícios sobre determinados itens gramaticais onde a língua é tradada de forma artificial ou, ainda, a tradução de textos escolhidos pelo professor e que nem sempre são de interesse do aluno. 
Portanto, se esse aluno fosse motivado a usar dentro da sala de aula essas ferramentas tecnológicas que eles usam fora do ambiente de ensino, tornaria o ensino de língua inglesa mais atraente e interessante para que viessem ter um bom desenvolvimento na aprendizagem da língua.

NTICs e ensino de LI

Para o ensino de uma língua estrangeira, em especial o inglês, sempre se fala em quatro habilidades que são: ler (Reading), escrever (Writing), ouvir (Listening) e falar (Speaking). Entretanto, sabemos que desenvolver todas essas habilidades nas escolas públicas não é uma tarefa fácil, por motivos de carga horária, salas numerosas, ausências de material instrucional, entre outros fatores. Sendo assim, é impossível exigir que os alunos saiam das escolas capazes de ler, escrever ouvir e falar inglês.

O ensino de LI tem carga horária reduzida e quebra de horários, por tanto sabemos que é impossível que o aluno saia falando o idioma fluentemente se ele ficar somente restrito no ambiente da sala de aula, por melhor que seja o ensino. Esse pouco tempo que tem na sala precisa ser utilizados de forma que desperte o aluno a buscar novas experiências com a língua.

Porém, sabemos que o conhecimento de uma língua estrangeira é direito do cidadão, pois é um método de inclusão social, mas apesar disso, não podemos deixar de dizer que ele é falho, principalmente quando se trata do nosso ensino público. Com as inúmeras falhas existentes, na maioria dos casos, os alunos chegam no ensino superior em um curso de letras, por exemplo, sem ter nenhum domínio da língua inglesa e isso acaba gerando grandes 
dificuldades na vida acadêmica desse aluno, e muitas vezes acabam concluindo o ensino superior e não conseguem, por exemplo, se comunicar usando o idioma.

Entretanto, o emprego das novas tecnologias poderá tornar o aprendizado mais fácil, pois é uma fonte inovadora de conhecimento. Aqueles que fazem o uso dessas ferramentas precisam estar em um aprendizado constante, segundo Kenski (2008, p.104), para que "possam sair do cerco fechado da sala de aula e do ambiente escolar para conectarem-se ao mundo".

No ensino-aprendizagem de língua inglesa podemos destacar a internet como ponto importante, pois possibilita que o aluno tenha acesso a várias mídias e, com isso, tornar o aprendizado mais atraente e divertido, além de favorecer a relação entre professor e aluno, possibilitando a troca de informação, receber feedback, fazer trabalhos em grupo, praticar o idioma entre outras coisas que ela nos possibilita realizar.

Segundo Peixoto e Siqueira, hoje a maioria dos alunos que chega à educação básica se insere na chamada Geração $\mathrm{Z}$, que também é conhecida por "nativos digitais", "homo zappiens", "geração digital" ou "geração internet". Eles também afirmam que:

Esses jovens estão cercados por informações praticamente o tempo todo que, devido ao grande volume em circulação, acabam se tornando obsoletas rapidamente. Como eles cresceram com a evolução das novas tecnologias, principalmente da internet, as NTIC foram incorporadas ao seu dia a dia, sendo utilizadas nos 
estudos, na vida diária e até nas relações sociais. (PEIXOTO; SIQUEIRA, 2015 p.68).

Eles ainda ressaltam que um ponto a ser considerado importante é que, além dessa geração estar mais envolvida com o consumismo, ela também está envolvida com a produção de informações online. Hoje, existe um certo conflito de gerações em sala de aula, entre professores, que nasceram na época em que ainda não existiam as novas tecnologias e alunos, que já nasceram rodeados por elas. Para acompanhar esses alunos da geração digital, “o professor também tem que mudar seu perfil e sua pratica pedagógica", afirma Xavier (2012, p.3). Ele ainda continua dizendo que o mestre precisa ser:

- Pesquisador, não mais repetidor de informação;

- Articulador do saber, não mais fornecedor único do conhecimento;

- Gestor de aprendizagens, não mais instrutor de regras;

- Consultor que sugere, não mais chefe autoritário que manda;

- Motivador da "aprendizagem pela descoberta", não mais avaliador de informações empacotadas a serem assimiladas e reproduzidas pelo aluno.

Esses pontos, sustentados por Xavier (2012), mostram que o professor quando adquire esse perfil, torna- se mais fácil para ele acompanhar esses alunos que estão cada vez mais aprendendo fora do ambiente escolar, com os recursos tecnológicos. Para obter sucesso durante o ensino de 
LI, o professor precisa adentrar no mundo tecnológico que seu aluno já domina com facilidade, o uso das NTICs, promovendo, assim, um feedback entre aluno e professor, de modo que ambos dominem os recursos e reconheçam que essa ferramenta é de grande importância para o ensino aprendizagem.

Aplicativos e ensino de L.I

Os aplicativos, mais conhecidos como APPs, são instalados em Smartphones, na maioria das vezes, de forma gratuita. Podem ser um grande aliado para quem quer aprender a língua inglesa sem ter nenhum custo, bastando apenas que tenha um aparelho celular para ter acesso a esses aplicativos. É uma ótima alternativa para quem deseja aprender inglês de forma prática e divertida. Mas é preciso entender que os aplicativos têm diferentes metodologias e também podem ser usados para aperfeiçoamento das quatro habilidades. Existe uma variedade de aplicativos para aprender o inglês. Eis alguns aplicativos que podem ser utilizados e as características de cada um:

$\diamond$ Duolingo: é focado no vocabulário, escrita e na compreensão oral, apresenta a cada dia, lições separadas por temas do nosso dia a dia. Talvez seja o mais conhecido e o mais utilizado quando o assunto é aprender inglês. Funciona no modo de jogo e os níveis vão avançando o que acaba tornando a aprendizagem divertida. É um aplicativo gratuito e possibilita o usuário estudar mais de quatro línguas ao mesmo tempo. É livre de anúncio. 
Figura 1: Aplicativo Duolingo

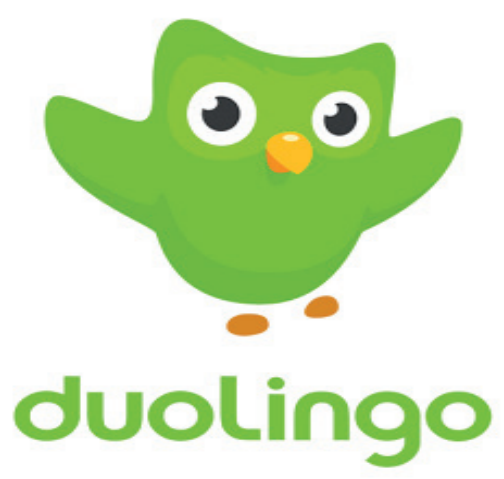

Fonte: https:/ / play.google.com/store/apps/details?id=com. duolingo\&hl=pt_BR

$\diamond$ Hello English: é um excelente aplicativo para quem não quer ficar somente restrito à memorização de palavras, mas receber explicações e dicas durante o processo. É apresentado como um dos melhores aplicativos de 2016, do Google. Suas funcionalidades são:

- 300 lições interativas $100 \%$ gratuitas com conversação em inglês, tópicos gramaticais e vocabulários. Todas as lições também funcionam no modo off-line;

- Conversar com professores, fazer perguntas sobre gramática e traduções;

- Praticar usando notícias diárias;

- Jogo de pratica de conversação sobre tópicos do dia a dia;

- Dicionário de 10.000 palavras. 
Figura 2: Aplicativo Hello English

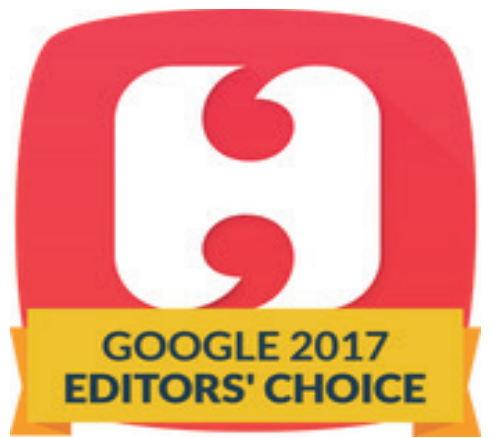

Fonte: https:/ / apkpure.com/br/hello-english-learn-english/ com.CultureAlley.japanese.english

$\diamond$ Lingualeo: é um aplicativo que permite que o usuário interaja com aprendizado e a prática do inglês, ideal também para quem não quer ficar só nas lições. Nele o usuário encontra vários tipos e conteúdos e seções para estudar de acordo com o que desejar e é adequado tanto para o público adulto quanto para o infantil. Para tanto, constitui-se de:

- Aprendizado de inglês gratuito;

- Dicionário pessoal com associações individuais, transcrições e áudio para cada palavra;

- Glossários temáticos com associações visuais;

- Treinos eficazes: tradução, construtor de palavras e compreensão oral;

- Possibilidade de escolher a melhor tradução;

- Dispositivo que permite que o progresso no aprendizado da língua seja monitorado em tempo real. 
Figura 3: Aplicativo Lingualeo

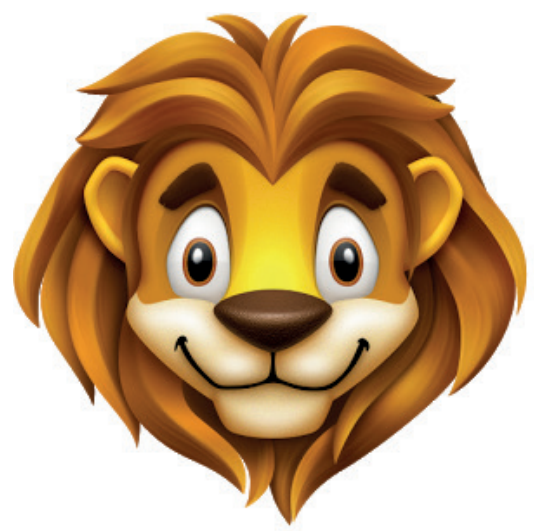

Fonte: https:/ / play.google.com/store/apps/details?id=com. lingualeo.android\&hl=pt_BR

Estes são alguns dos aplicativos que enriquece o aprendizado do aluno sendo um avanço no conhecimento e técnicas do professor de L.I e também possibilitam que os alunos aprendam fora da sala de aula. Segundo Gonçalves (2014):

Para a área educativa o número de APPs ainda é relativamente pequeno quando comparado a APPs de outras áreas como a de jogos por exemplo. Mas é notável já o interesse de desenvolvedores desses aplicativos para a área da educação.

Hoje com as funções oferecidas pelos Smartphones temos grandes possibilidades de acesso ao nosso próprio conhecimento, as informações surgem de maneira instantânea, o que vem ser de grande importância nos tempos 
atuais. Gonçalves (2014) afirma que no ensino de línguas os APPs são o destaque, por possibilitar a liberdade e pela facilidade de aprender uma determinada língua:

O ensino de línguas vem sendo destaque entre os APPs educativos, isso porque a liberdade e a facilidade de acesso a conhecimentos de línguas por meio de APPs têm despertado uma nova metodologia de aprendizagem, que nesse meio é autônoma, prática e gerenciável pelo aluno que os adaptam às suas necessidades de estudos (GONÇALVES, 2014, p. 3).

Os aplicativos fazem com que os usuários interajam e tenham facilidade em sua manipulação, oferecem também exercícios e avaliações práticas. Apesar dos benefícios que esses aplicativos trazem para a educação e pela quantidade de informações que eles carregam, eles não são tão valorizados, quando se trata de ensino/aprendizagem de línguas. Portanto, é necessário que seja despertado o interesse de se fazer trabalhos nessa área para mostrar que também é possível aprender a partir deles.

WhatsApp e ensino de L.I

O WhatsApp Messenger é um aplicativo de mensagens que permite aos seus usuários a troca de mensagens por aparelho móvel. O uso desse aplicativo tem grandes vantagens para o ensino de LI, sendo uma delas o fato de que os usuários podem criar grupos, enviar mensagens ilimitadas e fazer o compartilhamento de imagens, vídeos e 
áudios. O uso desse aplicativo no ensino de línguas, principalmente no ensino de LI, tem muitos aspectos positivos. Segundo Church e Oliveira o WhatsApp:

Éuma multiplataforma de mensagens instantâneas para smartphones. Ele permite que o usuário envie e receba informações de localização, imagens, vídeo, áudio e mensagens de texto em tempo real para indivíduos e grupos de amigos, sem custo (CHURCH E OLIVEIRA 2013, p.352).

O uso das NTICs no ambiente escolar não é um assunto novo nas pesquisas, pois muitos professores fazem o uso dessas tecnologias de alguma forma, mas, quando se fala em celular em sala de aula, não é um assunto aceito por parte de alguns: ou dizem que o uso do celular pode atrapalhar na aprendizagem, ou que a escola não é o ambiente adequado para se usar tal ferramenta. Já para Zardini (2015, p. 3), o uso de celulares e aplicativos de mensagens como o WhatsApp é relativamente novo, e, embora não tenha sido criado para ser utilizado no ensino, também apresenta boas oportunidades quando é usado para este fim, principalmente como ampliação das atividades de sala de aula.

O uso do WhatsApp pode ser, portanto, um grande aliado ao ensino de LI. Através de uma pesquisa feita por Zardini, percebe-se que o uso do aplicativo WhatsApp foi aceito pelos alunos como um ponto positivo. Ela afirma que:

O que mais se destaca nas falas desses alunos é o ambiente informal/ descontraído das discussões geradas 
pelo grupo, o aumento da comunicação entre os alunos, a troca de informação e conhecimento, a interação entre os alunos, o contato com a língua e a descontração propiciada pelo ambiente (ZARDINI, 2015, p.6).

Mas é importante ressaltar que o uso dessa ferramenta não dispensa o papel do professor, pois ele é indispensável e é através dele que será mostrado como fazer a utilização desses recursos para melhorar o ensino de LI. É uma forma descontraída de se aprender uma língua, dando possibilidades aos alunos de se comunicarem com outros falantes da língua no mundo todo, de forma simultânea e sem custo.

Outro ponto importante é que, para aqueles alunos que têm dificuldade de se expressar diante do grupo, o uso do WhatsApp possibilita mais tempo para organizar a maneira de se expressar, o que diminuirá sua ansiedade e o medo de se expor para o grupo da sala de aula, pois se dará através do ensino a distância, sem falar que através do aplicativo o aluno tem a possibilidade de praticar as quatro habilidades - reading, writing, listening e speaking ao mesmo tempo.

Antes, o acesso à internet era considerado precário, mas hoje, com as operadoras de telefonia celular e com a grande distribuição de pontos wi-fi, a comunicação tornou-se acessível até mesmo para pessoas que moram em localidades distantes dos centros urbanos. Além dos benefícios já citados anteriormente, existem outros apresentados pela UNESCO (PORVIR, 2013) que mostra treze bons motivos e dez recomendações para governos sobre o uso de tecnologias móveis na escola. 
Com todos esses motivos e recomendações apresentadas só reforça os benefícios que temos ao fazer utilização dessa ferramenta, e o quanto ela pode ajudar a melhorar o ensino/aprendizado de língua inglesa, pois ela oferece facilidade de aquisição, pode ser baixado em todos os celulares com o sistema android, Windows phone ou IOS e é um aplicativo popular entre os adolescentes e ele também permite que o aluno organize seu tempo de estudar.

Em uma pesquisa feita por Zardini (2015) sobre o uso do aplicativo de mensagem whatsApp, ela teve como experimento o grupo de 20 alunos que fizeram parte de um curso de extensão do CEFET- MG - CLIC (centro de língua e cultura). O grupo de alunos era composto por duas turmas com o mesmo nível de proficiência, e ela pôde constatar inicialmente uma certa timidez por parte dos alunos, necessitando de um incentivo para que eles interagissem, mas os resultados satisfatórios vieram ao longo prazo afirma Zardini:

De maneira bastante generalizada, pude constatar que a participação inicial foi bastante tímida, sendo necessárias muitas ações de incentivo para que os alunos participassem. Entretanto, apesar da timidez inicial, os resultados no longo prazo se mostraram satisfatórios. (ZARDINI, 2015, p. 4).

Portanto, é possível considerar que o uso desse recurso no ensino/aprendizagem é relativamente novo e que ainda possa existir uma certa rejeição, apesar de ter vários estudos já realizados sobre o uso positivo dessa ferramenta para o ensino. Assim como a sua utilização permite que o 
professor seja um pesquisador e deixe de repetir informações, ela também faz com que o aluno trabalhe na construção do seu próprio conhecimento, pois estão usando ferramentas de seu domínio. E com isso o professor motiva cada um deles a aprender mais sozinhos e em grupos.

Figura 4: Motivos e recomendações para usar tecnologias móveis em sala de aula

\begin{tabular}{|c|c|}
\hline Bons Motivos & Recomendações \\
\hline $\begin{array}{l}\text { Amplia o alcance e a } \\
\text { equidade da educação }\end{array}$ & $\begin{array}{l}\text { Criar ou atualizar } \\
\text { politicas ligadas ao }\end{array}$ \\
\hline $\begin{array}{l}\text { Melhora a educação em } \\
\text { áreas de conflito ou que } \\
\text { sofreram desastres naturais }\end{array}$ & $\begin{array}{c}\text { aprendizado móvel } \\
\text { Conscientizar sobre sua } \\
\text { importância }\end{array}$ \\
\hline Assiste alunos com deficiência & Expandir e melhorar \\
\hline $\begin{array}{l}\text { Otimiza o tempo na } \\
\text { sala de aula }\end{array}$ & $\begin{array}{l}\text { opçôes de conexão } \\
\text { Ter acesso igualitário }\end{array}$ \\
\hline $\begin{array}{c}\begin{array}{c}\text { Permite que se aprenda em } \\
\text { qualquer hora e lugar }\end{array} \\
\text { qual }\end{array}$ & $\begin{array}{c}\text { Garantir equidade } \\
\text { de gênero }\end{array}$ \\
\hline $\begin{array}{c}\text { Constrói novas comunida- } \\
\text { des de aprendizado }\end{array}$ & $\begin{array}{c}\text { Criar e otimizar } \\
\text { conteúdo educacional }\end{array}$ \\
\hline $\begin{array}{c}\text { Dá suporte à } \\
\text { aprendizagem in loco }\end{array}$ & Treinar professores \\
\hline $\begin{array}{l}\text { Aproxima o aprendizado } \\
\text { formal do informal }\end{array}$ & $\begin{array}{l}\text { Capacitá-los usando } \\
\text { tecnologias móveis }\end{array}$ \\
\hline $\begin{array}{l}\text { Provê avaliação e } \\
\text { feedback imediatos }\end{array}$ & $\begin{array}{l}\text { Promover o uso seguro, } \\
\text { responsável e saudável }\end{array}$ \\
\hline Facilita o aprendizado & das tecnologias \\
\hline personalizado & Usá-las para melhorar a \\
\hline $\begin{array}{c}\text { Melhora a aprendizagem } \\
\text { contínua }\end{array}$ & $\begin{array}{c}\text { comunicação e a gestão } \\
\text { da educação }\end{array}$ \\
\hline Melhora a comunicação & \\
\hline $\begin{array}{c}\text { Maximiza a relação custo- } \\
\text { benefício da educação }\end{array}$ & \\
\hline
\end{tabular}

Fonte: adaptado de Porvir, 2013. 


\section{Aplicativo de mensagem e ensino de LI: sugestão de atividade}

Nesta seção, será apresentado um quadro sugestivo mostrando a utilização das novas tecnologias no ensino de língua inglesa, seguindo um propósito de que precisamos considerar que seu uso tornou-se uma necessidade da qual não podemos prescindir. Em seguida, será apresentada uma proposta de ensino direcionada ao nível escolar fundamental II, enfatizando o aplicativo de mensagem WhatsApp como instrumento de trabalho nas aulas de língua inglesa. A intenção do desenho da atividade é que esta proposta possa servir como base para outros professores que desejam fazer o uso desse aplicativo em suas aulas.

O uso do aplicativo deve estar no contexto do conteúdo proposto para uma determinada aula, seja ela teórica ou prática, facilitando a mediação entre aluno, professor e o assunto abordado no plano de aula. Dessa forma, o uso do aplicativo irá proporcionar e desenvolver habilidades no aprendizado do aluno de uma forma inovada e satisfatória. Pensando nisso, elaboramos três grupos, mostrando como utilizá-la de forma produtiva e para aproximação da comunidade escolar em geral.

- Corpo docente: É essencial a aceitação desses profissionais para adoção das novas tecnologias na escola, pois eles é quem irão lidar primeiramente com elas e, portanto, é necessário que estejam a favor da mudança. Desse modo, irão ser os motivadores para o uso das tecnologias, embora seja preciso que eles tenham ajuda para inseri-las da 
melhor forma, como, por exemplo, treinamentos e aulas com profissionais de informática, deixando-os mais seguros para utilizar o aplicativo na sala de aula. O WhatsApp pode ser usado pelos professores para facilitar a troca de experiências sobre suas práticas pedagógicas, indicar materiais, livros e atividades.

- Pais e responsáveis: Sabemos que o envolvimento dos pais é muito importante na formação de seus filhos, mas nem sempre eles conseguem fazer o acompanhamento necessário. Sendo assim é importante que exista sua participação na escola, sendo informados do calendário escolar acerca dos conteúdos e recursos usados pelos professores em atividades para seus filhos. Essa mediação entre pais/responsáveis e escola muitas vezes é dificultada por motivos superiores e, com o uso das novas tecnologias, possibilita-se aproximar os pais para que, juntos com os docentes, tomem decisões sobre a implementação do aplicativo de mensagens em sala de aula, que serão fundamentais no aprendizado dos alunos e principalmente na socialização entre pais e mestres. Com essa ferramenta, pode-se criar um grupo para aproximar os pais da rotina escolar de seus filhos, podendo ser usada para enviar recados gravados ou escritos, agenda de atividades, informações de possíveis eventos, comunicados importantes, relatório do desempenho escolar dos filhos.

- Alunos: Como os alunos já nascem imersos nas novas tecnologias, é provável que não haja nenhuma rejeição na implementação do aplicativo 
por parte deles, quanto ao uso das tecnologias durantes as aulas, auxiliando em sua educação. Mesmo assim, é preciso um acompanhamento em seu uso para que eles não saiam do foco, que é o seu aprendizado. É de grande estratégia do professor explicar as vantagens e seus objetivos com relação ao ensino de língua inglesa antes de fazer o uso da nova tecnologia, pois, em relação aos aplicativos, os alunos vêm com um conceito formado de que ele só serve para trocar mensagens, com amigos e parentes. Dessa forma, o professor apresenta a ferramenta mostrando a ludicidade em relação ao ensino e aquisição de cada um e o uso irá desenvolver as habilidades de ouvir, ler, escrever e falar em inglês.

Diante das apresentações da inserção do uso da tecnologia no ambiente escolar de uma forma que unificou todos os responsáveis pela educação eaprendizagem dos alunos, podemos ressaltar a importância tanto do uso de novos aplicativos, como o WhatsApp, quanto da presença dos pais/responsáveis na escola. Apresentamos a seguir o modelo da proposta de ensino utilizando o aplicativo de mensagens WhatsApp, como tarefa de casa para a prática oral, escrita e de vocabulário.

Objetivo: usar o aplicativo WhatsApp para que o aluno possa praticar a oralidade, a escrita e a aquisição e manejo de vocabulário em LI.

Conteúdo: o conteúdo que servirá como tema para mensagens orais e escritas no WhatsApp será relacionado com temas desenvolvidos durante as aulas. 
Desenvolvimento do tema: o desenvolvimento das atividades será realizado durante cada unidade temática trabalhada em sala.

Materiais: Aparelho de telefonia móvel celular, smartphone, ou tablet com aplicativo WhatsApp instalado.

Avaliação: Os alunos serão avaliados através da participação nas atividades no grupo do WhatsApp, e será considerada também sua evolução na escrita, na oralidade e no desenvolvimento do vocabulário.

Antes de tudo o professor deverá se certificar se todos possuem um aparelho móvel como, por exemplo, celular smartphone ou tablet. Em seguida, cada um precisará instalar o aplicativo em seus aparelhos com ajuda do professor. Talvez não seja necessária a instalação, por ser um aplicativo popular e muito utilizado hoje em dia.

Depois de se certificar de que todos os aparelhos estão com o aplicativo, junto com a turma, o professor irá criar um grupo no WhatsApp para a comunicação dos alunos como trabalho extra-sala. No final de cada unidade temática que for sendo trabalhada com eles em sala, será proposta pelo professor uma atividade escrita e oral para ser trabalhado o vocabulário que será desenvolvido, através do aplicativo, lidando assim com o desenvolvimento das habilidades propostas.

Em dupla, o professor irá selecionar com base no vocabulário que foi utilizado durante as aulas em sala, frases e palavras e deverá escolher quem da dupla ficará responsável pela gravação e quem ficará encarregado da escrita, lembrando que quem ficar responsável pela escrita vai estar trabalhando com a atividade de compreensão oral também. O professor irá pedir que o aluno grave uma 
frase ou palavra das que foram propostas e envie para o outro e, sempre o que receber o áudio ouvirá e retornará por escrito o que entendeu por mensagem de texto.

Como essa atividade será feita através do grupo é interessante que o professor imponha critérios para as duplas para evitar desorganização. O interessante é que a cada atividade o professor troque a ordem dos alunos. Por exemplo, o que gravou na primeira atividade irá escrever na segunda e vice-versa.

O tempo para a atividade terá duração de 50 minutos, para que todas as duplas participem. Depois os alunos serão avaliados pelo seu desempenho, participação e principalmente pela sua evolução nas atividades. O possível problema, antecipadamente previsto, é uma falha na conexão com a internet, pois o aplicativo só funciona se houver sinal, de preferência wi-fi.

Embora esta proposta tenha sido elaborada para se trabalhar a compreensão oral, escrita e vocabulário, vale lembrar que são inúmeras as atividades que podem ser desenvolvidas através desse aplicativo e é possível o aprendizado do inglês por meio dele, principalmente pela familiaridade no trato com tal recurso tecnológico.

\section{Considerações Finais}

Esta pesquisa teve como principal objetivo despertar o interesse dos profissionais da área educativa, principalmente os professores de língua inglesa, a serem engajados nesta corrente que busca incentivar o uso das novas tecnologias como ferramenta para apoiar a construção do conhecimento. 
Procuramos demonstrar que, através delas, podemos criar metodologias criativas, inovadoras e dinâmicas, na urgência de atuação de uma prática docente reflexiva, pois sabemos que, para tal, precisamos revisar nossas formas de ensinar e pensar na modificação não só para si próprios, mas para todos que fazem parte da comunidade escolar e visar principalmente às necessidades dos alunos.

Neste sentido, demonstramos que as novas tecnologias da informação e comunicação podem trazer melhorias para o ensino de língua inglesa e, como tais, podem ser consideradas como método de ensino, uma vez que estes remetem às formas pelas quais o professor trabalha os diversos conteúdos com seus alunos, com o fim de alcançar o objetivos propostos.

Assim, o professor que fizer a utilização das NTICs tende a favorecer essa nova geração, que já nasce imersa nelas, contexto que propicia ao professor e ao aluno oportunidades de interação, através de recursos digitais que podem ser inseridos na prática pedagógica, seja no espaço da sala de aula ou fora dela.

Já no que tange ao campo do ensino/aprendizagem de língua inglesa, em que pese o fato de termos feito menção sobre a existência de diversos aplicativos, como o Duolingo, o Hello English, o Lingualeo, mais voltados para o aprendizado do inglês, como língua adicional, sabemos que essa área precisa ser vista com outro olhar e dada uma importância maior. Os aplicativos possibilitam que o aluno tenha facilidade de aprender determinada língua, sem custo e de modo dinâmico.

Em seguida, discorremos acerca do foco principal deste trabalho, que é a utilização do aplicativo WhatsApp, como recurso auxiliar nas aulas de língua inglesa. Foram 
apresentadas algumas formas de se trabalhar com ele, para a aproximação de toda a comunidade escolar e também para melhorar o aprendizado dos alunos: apesar de não ter sido desenvolvido para esse intuito, de caráter pedagógico, sabemos da possibilidade de sucesso em práticas de ensino/aprendizagem de a língua inglesa especialmente quanto às atividades de escuta, escrita e desenvolvimento de vocabulário.

Podemos acrescentar que, a partir do panorama aqui desenvolvido, pôde-se constatar ser possível imprimir mudanças com relação ao ensino/aprendizagem de língua inglesa, principalmente quanto à importância dada ao uso das NTICs como auxiliadoras no processo.

Esperamos, portanto, que o presente estudo possa vir contribuir não só para a aprendizagem da compreensão oral, escrita e vocabulário, mas para fomentar o desenvolvimento de outras habilidades e que, através da conscientização dos profissionais do ensino de língua inglesa com relação ao uso dessas novas ferramentas, estes possam enxergar as múltiplas possibilidades de atividades que as novas tecnologias nos permitem desenvolver.

\section{Referências}

BASSO, E. Adolescentes e a aprendizagem de uma língua estrangeira: características, percepções e estratégias. In: ROCHA, C,: BASSO, E. Ensinar e aprender lingua estrangeira nas diferentes idades: reflexão para professores e formadores. São Carlos: editora Claraluz, 2008.

CHAPELLE, C. Computer applications in second language acquisition. Cambridge: Cambridge University Press, 2001. 
CHURCH, K.; OLIVEIRA, R. What's up with WhatsApp? Comparing Mobile Instant Messaging Behaviors with Traditional SMS. 15th International Conference on HumanComputer Interaction with Mobile Devices and Services, 2013.

DONNINI, Lívia; PLATERO, Luciana. WEIGEL, Adriana. Ensino de língua inglesa. São Paulo: Cengage Learning, 2010.

GANDOUR, D. A reflexão crítica e a utilização de textos no ensino de língua estrangeira. In: ARAÚJO, S.; GALVÃO, M.; VIAN JR. O. O ensino e a pesquisa em língua inglesa na universidade: mapeando caminhos, explorando novas trilhas. Natal: Editora da UFRN, 2014.

GIL, Antonio Carlos. Métodos de pesquisa social. São Paulo: Atlas, 2008.

GONÇALVES, Jessica. Inglês na palma da mão: possibilidades de aprendizagem através dos dispositivos móveis conectados à internet. Revista de Estudos Acadêmicos de Letras. Cáceres, v. 7, n. 1, 2014.

KENSKI, V. M. O ensino e os recursos didáticos em uma sociedade cheia de tecnologias. In: VEIGA, Ilma (Org.). Didática: o ensino e suas relações. Campinas: Papirus, 1996.

KENSKI, V. M. Educação e tecnologias: o novo ritmo da informação. Campinas: Papirus, 2008.

LOPES, Diana. As Novas Tecnologias e o Ensino de Línguas Estrangeiras. Recife, Revista Científica Tecnologus, v. 6, 2012. 
LEFFA, Vilson. Metodologia do ensino de línguas. In: BOHN, H. I.; VANDRESEN, P. (Org.) Tópicos em linguística aplicada: o ensino de línguas estrangeiras. Florianópolis: Ed. Da UFSG, 1988, p. 211-236.

MALEY, A. Squaring the circle - Reconciling materials as constraint with materials as empowerment. In B.Tomlinson (ed.). Materials development in language teaching. Cambridge: Cambridge University Press, 1998, p. 279-94.

OLIVEIRA, Luciano. Métodos de ensino de inglês: teorias, práticas, ideologias. São Paulo: Parábola, 2014.

. Aulas de inglês: do planejamento à avaliação. São Paulo: Parábola, 2015.

PAIVA, V.L.M. O uso da tecnologia no ensino de línguas estrangeiras: breve retrospectiva histórica, 2006. Disponível em: www.veramenezes.com/techist.pdf.

PAIVA, V.L.M. O ensino de língua estrangeira e a questão da autonomia. In: LIMA, D.C. (Org.) Ensino aprendizagem de língua inglesa: conversas com especialistas. São Paulo: Parábola Editorial, 2009.

PEIXOTO, Roberta; SIQUEIRA. Domingos. Novas tecnologias nas aulas de inglês da escola pública: entre o desejável e o possível. Hipertextus, Revista Digital. Recife, v. 13, set. 2015. Disponível em < http://www.hipertextus.net/ volume13/revista-hipertextos-artigo4.pdf $>$

PORVIR. 10 dicas e 13 motivos para usar celular na aula. Site Porvir. 2013. Disponível em: <http://porvir. 
org/porfazer/10-dicas-13-motivos-para-usar-celularna-aula/20130225>. Acesso em: 29 de setembro de 2017.

SANTOS, Tássia; BEATO, Zelina; ARAGÃO, Rodrigo. As TICs e o ensino de línguas. Disponível em: http://www. uesc.br/eventos/sepexle/anais/10.pdf. Acesso em: 16 abr. 2012.

XAVIER, A. C. S. Letramento digital e ensino. Disponível em: http:/ / www.ufpe.br/ nehte/artigos/Letramento\%20 digital $\% 20 \mathrm{e} \% 20$ ensino.pdf. Acesso em:31 de agosto de 2017.

ZARDINI, A.S. O uso do whatsApp na sala de aula de língua inglesa-relato de experiência em um curso de idiomas. In: Simpósio sobre Materiais e Recursos Didáticos, 4., 2015, Rio de Janeiro. Anais... Rio de Janeiro: PUC/RJ, 2015. 